\title{
ИСПОЛЬЗОВАНИЕ ТЕРМОГРАФИИ АЛЯ ОПРЕДЕЛЕНИЯ ПРОБОДАЮЩИХ СОСУДОВ ПЕРЕДНЕЙ БРЮШНОЙ СТЕНКИ ПРИ РЕКОНСТРУКТИВНЫХ ОПЕРАЦИЯХ НА ГРУДИ
}

\author{
А. Ю. Дабижа
}

Национальный институт хирургии и трансплантологии имени А. А. Шалимова НАМН Украины, г. Киев

\section{DETECTION OF PERFORATOR VESSELS OF ABDOMINAL WALL WITH THERMOGRAPHY AT THE BREAST RECONSTRUCTION}

\author{
A. Yu. Dabizha \\ Shalimov National Institute of Surgery and Transplantology, Kiev
}

\section{Рефрерат}

Проанализированы результаты исследования прободающих сосудов (ПС) передней брюшной стенки с помощью термографии. Проведен сравнительный анализ с данными ультразвукового исследования и компьютерной томографии (КТ) с контрастированием. Включение в состав лоскута ПС, выявленных по данным термографии, позволило обеспечить адекватную перфузию в TRAM-лоскуте.

Ключевые слова: реконструкция груди; прободающие сосуды; термография.

\section{Abstract}

Results of definition the perforator vessels of abdominal wall with a termography were analysed. The comparative analysis with data of ultrasonography and a computer tomography with contrast was carried out. Inclusion in structure of a flap the perforator vessels revealed by means of a termography has allowed to provide adequate perfusion in a TRAM flap.

Keywords: breast reconstruction; perforator vessels; thermography.

Полная или частичная утрата грудной железы (ГЖ) может быть следствием травматического повреждения, ожога, гнойно-некротических процессов и ряда других менее значимых причин. При этом основной причиной является мастэктомия по поводу рака ГЖ. Полная или частичная утрата ГЖ обусловливает психо-эмоциональные нарушения, социальную дезадаптацию пациентки [1]. В настоящее время реконструкция груди является одним из основных этапов реабилитации пациенток, улучшающим качество их жизни $[1,2]$.

«Золотым стандартом» реконструкции груди является транспозиция или свободная микрохирургическая пересадка TRAM-лоскута в различных модификациях: пересадка полнослойного TRAM-лоскута; TRAM-лоскута с включением в его состав минимального количества мышечной ткани («musclesparing»); перфорантного TRAM-лоскута («diep-flap»). Четкое представление о кровоснабжении лоскута, который планируют выделять в зоне гарантированного питания, позволяет уменышить риск возникно- вения некроза и липосклероза [2, 3].

Васкуляризация этих тканей осуществляется посредством нижней надчревной артерии, формирующей сеть крупных прободающих артерий как медиального, так и латерального ряда [2, 4 - 7].

Поэтому принципиально важно правильно оценить кровоснабжение лоскута, в частности, места выхода ПС. В целях изучения ПС в пределах границ лоскута используют ультразвуковое дуплексное сканирование (УЗДС), магниторезонансную томографию (МРТ) или КТ с контрастированием, ангиографию. Одним из наименее затратных, простых и эффективных методов является термография [8, 9].

В последнее время в зарубежной литературе появились сообщения об успешном использовании этого метода в различных модификациях.

Мы использовали термограф фирмы FLIR с программным обеспечением iOs [9].

Цель исследования: изучить возможности мобильного термографа FLIR для определения мест выхода ПС передней брюшной стенки при реконструкции груди с использо- ванием TRAM-лоскута в различных модификациях.

\section{МАТЕРИАЛЫ И МЕТОДЫ ИССЛЕДОВАНИЯ}

Кровоснабжение передней брюшной стенки, места выхода ПС изучены у 27 пациенток, из них у 6 после мастэктомии осуществляли реконструкцию груди с использованием мягких тканей передней брюшной стенки (TRAM - лоскут в различных модификациях). У 21 здоровых женщин (волонтеров) проводили термографию и УЗДС сосудов передней брюшной стенки с применением стационарного и переносного аппаратов.

Сравнивали различные методы диагностики для оценки достоверности локации ПС по данным термографии с использованием УЗДС и КТ с контрастированием.

Термографию проводили с использованием термографа FLIR, подключенного к айфону 5 или 6S, данные обрабатывали в программе FLIR ONE и FLIR ONE PAINT, чTO позволяло определять локализацию сосудов в разных цветовых спектрах и разницу температуры. 
После предварительного обследования пациентки проводили термографию на расстоянии $70-100$ см после 3 мин адаптации к окружающей температуре (без одежды). Фотофиксацию проводили при комнатной температуре $\left(22^{\circ} \mathrm{C}\right)$ и влажности около 50\%. Определяли ПС, маркировали их на передней брюшной стенке и проводили УЗДС в целях уточнения их локализации. У 6 пациенток, которым планировали реконструкцию груди с использованием TRAM-лоскута, перед термометрией проводили MPТ с контрастированием.

Приводим наблюдение.

Пациентка М., 43 лет, госпитализирована в клинику для реконструкции левой груди после мастэктомии (2011). В анамнезе сведения о кесаревом сечении (1986). Показана реконструкция груди путем свободной микрохирургической пересадки TRAM-лоскута.

После предварительного обследования пациентке проведена МРТ с контрастированием для определения питающих сосудов лоскута, ПС передней брюшной стенки, реципиентных сосудов. После адаптации к комнатной температуре проведена термография.

На основе анализа полученных данных выполнена маркировка ПС на коже передней брюшной стенки в подчревной области. Полученные результаты совпали с данными МРТ (рuс. 1).

Для контроля результата перед операцией проведено УЗДС с использованием переносного аппарата. Во время выделения лоскута идентифицировали ПС, соответствовавшие маркировке (рис. 2). Выделен лоскут с включением в его состав ПС.

После подготовки реципиентных сосудов (внутренних грудных артерии и вены) выполнена свободная микрохирургическая пересадка TRAM-лоскута. После операции нарушения гемодинамики лоскута не наблюдали (рис. 3).

\section{РЕЗУЛЬТАТЫ}

\section{И ИХ ОБСУЖДЕНИЕ}

Реконструкция груди с использованием тканей передней брюшной

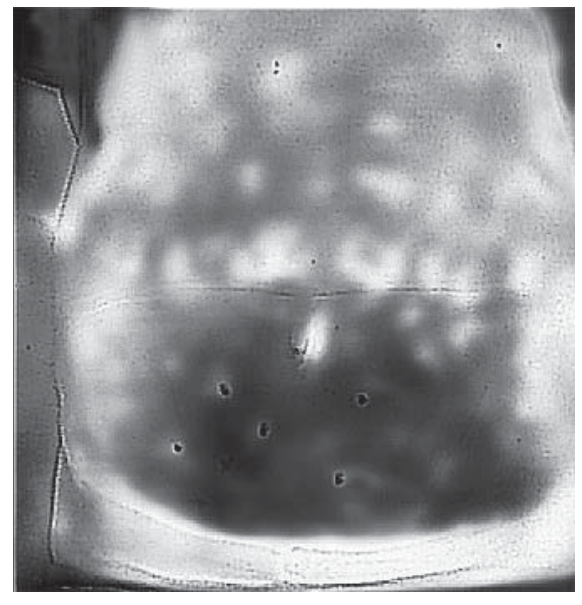

Рис. 1.

Участки, маркированные по данным МРТ, совпали с данными, полученными при термографии.

стенки является перспективным направлением в реконструктивной хирургии, использование TRAM-лоскута в мире считают «золотым стандартом».

Одним из осложнений, возникающих в послеоперацинном периоде, является нарушение кровоснабжения лоскута, что обусловливает некроз отдельных участков общего покрова, липонекроз, липосклероз $[2,3]$. Поэтому лоскут следует выделять в границах гарантированного кровоснабжения, на основе особенностей васкуляризации (перфорасом). С этой целью проводят различные инструментальные исследования, в том числе МРТ, КТ с ангиографией, УзДС. Эти методы, используемые в предоперационном периоде, сложны, финансово емки, требуют дополнительного времени. Одним из перспективных методов исследования является термография с использованием мобильного термографа фирмы FLIR, работающего на программной платформе iOs [8, 9].

Оценивая результаты предоперационного обследования с использованием инструментальных методов, можно сказать, что данные локации ПС с помощью термографии полностью соответствуют данным, полученным при других исследованиях. Для получения наиболее точных данных исследование тканей проводят после адаптационного периода в течение 3 мин, иначе участки тела, ранее покрытые одеждой, могут быть ошибочно расценены как

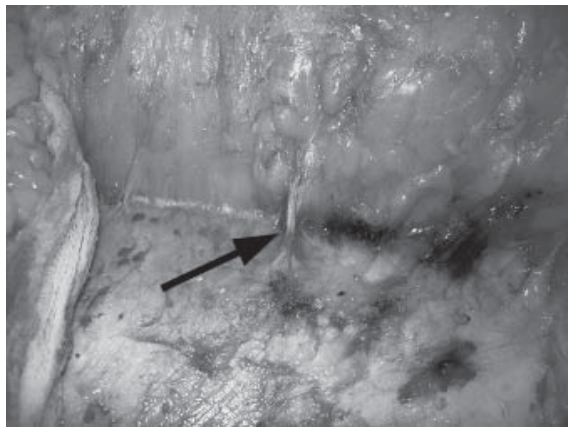

Рис. 2.

Выделена прободающая артерия, кровоснабжающая кожу передней брюшной стенки, соответствовавшая маркировке по данным термографиии.

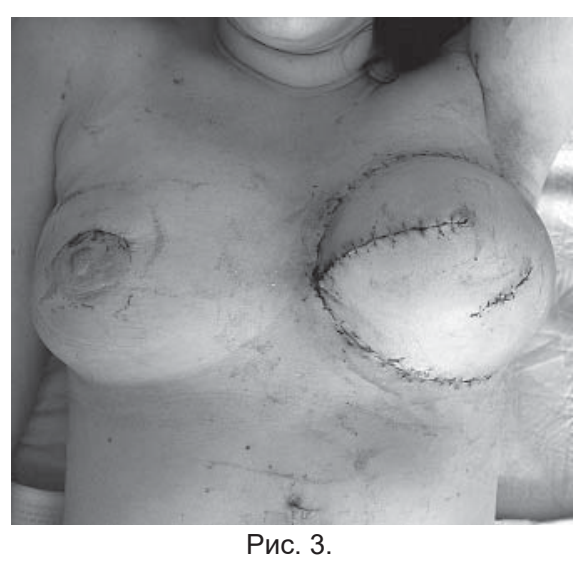

Ближайший послеоперационный период. TRAM - лоскут без признаков нарушения гемодинамики.

«горячие точки» выхода ПС. Для подтверждения локации этих сосудов следует дополнительно проводить УЗДС.

Данные термографии, определяющие точки выхода ПС на коже передней брюшной стенки, как правило, несколько отличаются от проекции их выхода в области апоневроза прямых мышц живота. Это, очевидно, обусловлено ходом самого ПС.

Использование программы FLIR ONE и FLIR TOOL позволяет определить разницу температуры в точке выхода ПС из окружающих тканей. При этом над разными ПС разница температуры может достигать $0,2^{\circ} \mathrm{C}$, что косвенно свидетельствует о доминировании (по скорости кровотока, диаметру, развитию субдермального сплетения) тех или иных ПС.

\section{выводы}

1. Термография является бесконтактным, неинвазивным, техниче- 
ски простым методом исследования, позволяющим достаточно точно определить места выхода наиболее значимых ПС на передней брюшной

\section{ЛИТЕРАTУPA/REFERENCES}

1. Galich SP, Dabizha AYu, Smolanka II, i dr. Vtorichnaya rekonstruktsiya grudi posle mastektomii po povodu raka. Onkologiya. 2008;10(3):328-32. [In Russian].

2. Nahabedian MY, Momen B, Galdino G, Manson PN. Breast reconstruction with the free TRAM or DIEP flap: patient selection, choice of flap, and outcome. Plast Reconstr Surg. 2002;110(2):466-74.

3. Khansa I, Momoh AO, Patel PP, Nguyen JT, Miller MJ, Lee BT. Fat necrosis in autologous abdomen-based breast reconstruction: a systematic review. Ibid. 2013;131(3):443-52.

4. Kroll S. Fat necrosis in free transverse rectus abdominis myocutaneous and deep inferior epigastric perforator flaps. Ibid. 2000;106(3):576-83.

5. Wong C, Saint-Cyr M, Mojallal A, et al. Perforasomes of the DIEP flap: Vascular anatomy of the lateral versus medial row perforators and clinical implications. Ibid. 2010;125(3):772-82.
6. Koshima I, Soeda S. Inferior epigastric artery skin flap without rectus abdominis muscle. Br J Plast Surg. 1989;142:645-8.

7. Blondeel P, Van Landuyt K, Monstrey S, et al. The "Gent" consensus on perforator flap terminology: preliminary definitions. Plast Reconstr Surg. 2003;112(5):1378-83.

8. Слесаренко СВ, Бадюл ПА. Применение инфракрасной термографии для оптимизации планирования перфорантных лоскутов. Пластична реконструктивна і естетична хірургія. 2016;1-2:50-60. [In Russian].

9. Hardwicke JT, Osmani O, Skillman JM. Detection of perforators using smartphone thermal imaging. Plast Reconstr Surg. 2016;137(1):3941. 